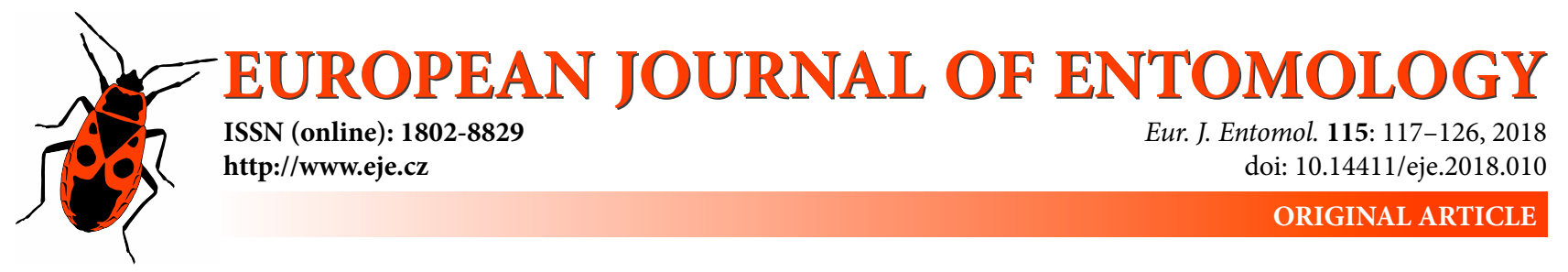

\title{
Conspectus of Australian Brachystomellidae (Collembola) with description of new species of Rapoportella and redescription of Cassagnella anomala
}

\author{
Penelope GReenslade \\ Environmental Management, School of Applied and Biomedical Science, Federation University, Ballarat, Victoria 3353, Australia, \\ and Division of Biology, Australian National University, Australian Capital Territory, 0200, Australia; \\ e-mail: p.greenslade@federation.edu.au
}

Key words. Collembola, Brachystomellidae, Australia, review, morphology, distribution, key to genera, Rapoportella edwardi sp. n., S-chaetae, cuticular plates, drying climate, conservation values, ecosystem function

\begin{abstract}
As part of a modern review of all Australian Collembola families, a key is provided to the nine genera of Brachystomellidae currently known from Australia, their morphology is compared, their distribution within and outside Australia is noted and the high diversity of genera in southern regions emphasised. Three Australian genera are endemic, five are also found in South America, South Africa and/or New Zealand and one has a cosmopolitan distribution. The distribution, ecology and habitat preferences of Australian genera are compared. Two genera, Cassagnella Najt \& Massoud and Rapoportella Ellis \& Bellinger, are newly diagnosed and additions to the description of $C$. anomala Womersley are given. Australian Cassagnella species appear restricted to southern, humid regions and $C$. anomala possesses some characters that indicate it is adapted to living in habitats that are periodically flooded. A new species, Rapoportella edwardi sp. $\mathrm{n}$. is described in the rarer genus from drier eucalypt forests. The effect of agricultural practices on an introduced species of Brachystomella is noted and its indicator value emphasised. Possible threats to the endemic genera and species are noted.
\end{abstract}

ZooBank Article LSID: 15994701-DE68-4D66-AFCC-651D49E4589C

\section{INTRODUCTION}

The family Brachystomellidae is widespread and abundant in the southern half of Australia. It comprises eight or nine genera (see Table 1); three of which are endemic, four or five occur in other southern regions and one, Brachystomella Ågren, 1903, is near cosmopolitan (Greenslade, 2017). Although some undescribed Australian genera are in collections, a fuller understanding of the current composition of the family is indicated which I provide here.

Worldwide the family Brachystomellidae currently consists of 18 genera and 124 species (Bellinger et al., 2018) with many species, even those already in collections, undescribed. As some regions are not adequately or not at all sampled, it is likely that these figures represent only a fraction of the total world fauna (Greenslade, unpubl. data). All described genera except for one, Brachystomella, are likely to be Gondwanan in origin as they occur, almost exclusively, in the Southern Hemisphere including Neotropics, although Rapoportella Ellis \& Bellinger, 1973 also occurs in Mexico. Of the remaining genera, nine occur in South America (Najt \& Weiner, 1996). With the eight known from Australia, the generic richness of the family, as currently known, is similar for both Australia and South America. The faunas of the other two southern continents, South Africa (six species in three genera) and New Zealand (four species in two genera) are less known.

Most of the world genera (15) are represented by five or fewer described species apart from three, Brachystomella with 68 species, Setanodosa Salmon, 1942 with 12 and $R a$ poportella with 10 . This indicates that either the family as a whole is largely relictual or many species await description. A key to world genera, based on a few morphological characters, has been written and is available online (https:// www.collembola.org/key/bracidae.htm). However, some smaller genera are not well characterised, so the key should be followed with this in mind. All species known are listed on the same site.

After examination of identified specimens, Najt et al. (2005) provided a phylogeny of Brachystomellidae using 54 morphological characters of 26 species belonging to 16 genera, with the resulting tree suggesting some generic synonymies especially in Brachystomella. For a more comprehensive resolution of generic boundaries, molecular analysis is indicated using more species. This is because 
some characters used for generic diagnoses, such as number of teeth on maxilla and its shape, presence of pigmentation, number of S-chaetae on anterior three abdominal segments, presence and size of a sensorial rasp on antennal segment IV and shape of mucro vary within a genus or are unknown. In particular, the synonymy of genus Massoudella Ellis \& Bellinger, 1973 with Brachystomellides Arlé, 1959 is not fully resolved as although Najt \& Weiner (1996) proposed the synonymy they did not fully justify it by documenting all diagnostic characters in common. Table 1 provides a list of key characters of the type species for Cassagnella and Rapoportella with species recorded from Australia based in recent literature.

Altogether 21 species are recorded from the nine genera known from the continent and its off-shore islands (Greenslade, 2017). However, the family has not been revised recently and the Australian fauna is estimated to consist of around 50 species. I provide here a key to genera found in Australia, a brief summary of their distribution and composition and a reappraisal of two genera, including a redescription of Cassagnella anomala (Womersley, 1933), and description of a new species of Rapoportella. The defining characters of the Australian genera are given in Table 1. This is an extension of joint work begun with the late Judith Najt in 1983.

\section{MATERIAL AND METHODS}

Specimens studied were all from South Australian Museum, Adelaide and included type material of Herbert Womersley. They had been cleared in Nesbitt's solution, mounted in Berlese medium and were examined with a Nikon phase contrast microscope. Figures were drawn using a camera lucida and enhanced in Photoshop. All figures and the description of $C$. anomala were made by Judith Najt in the Museum national d'Histoire naturelle, Paris in 1983 using different equipment.

Table 1. Characters of Australian Brachystomellidae genera based on type species from literature sources. $R$ - rectangular, $E$ - elongate. A - absent, P - present, L - lobed, S - straight, La - large, Sm - small, ? - unknown. *Brachystomellides may not be present in Australia.

\begin{tabular}{|c|c|c|c|c|c|c|c|c|c|}
\hline $\begin{array}{l}\text { Type } \\
\text { species }\end{array}$ & $\begin{array}{c}\text { Massoudella } \\
\text { geniculata } \\
\text { (Womersley, } \\
\text { 1934) }\end{array}$ & $\begin{array}{c}\text { Bonetella } \\
\text { terricola } \\
\text { (Womersley, } \\
1934)\end{array}$ & $\begin{array}{c}\text { Brachystomella } \\
\text { parvula } \\
\text { Schäffer, } 1896\end{array}$ & $\begin{array}{l}\text { Brachystomellides } \\
\text { compositus } \\
\text { (Arlé, 1959) }^{*}\end{array}$ & $\begin{array}{l}\text { Cassagnella } \\
\text { alba Najt \& } \\
\text { Massoud, } \\
1974\end{array}$ & $\begin{array}{c}\text { Rapoportella } \\
\text { rhodosoma } \\
\text { (Rapoport, } \\
\text { 1962) }\end{array}$ & $\begin{array}{c}\text { Salvarella } \\
\text { wallacei } \\
\text { Greenslade \& } \\
\text { Najt, } 1987\end{array}$ & $\begin{array}{c}\text { Setanodosa } \\
\text { tetrabrachta } \\
\text { Salmon, } \\
1942\end{array}$ & $\begin{array}{c}\text { Subclavontella } \\
\text { acantha } \\
\text { (Womersley, } \\
\text { 1933) }\end{array}$ \\
\hline Locality & Australia & Australia & Germany & Brazil & Argentina & Argentina & Australia & N. Zealand & Australia \\
\hline Maxilla & $\mathrm{R}$ & $\mathrm{R}$ & $\mathrm{R}$ & 1 hook & $E$ & $E$ & $E$ & $\mathrm{R}$ & 1 hook \\
\hline $\begin{array}{l}\mathrm{PAO} \\
\text { (vesicles) }\end{array}$ & $P(4)$ & $A$ & $P(5-6)$ & $P(4-5)$ & $P(10)$ & $P(7)$ & $A$ & $P(5-6)$ & A \\
\hline Shape mucro & $\mathrm{L}$ & $\mathrm{S}$ & $\mathrm{S}$ & $\mathrm{L}$ & $\mathrm{S}$ & $\mathrm{S}$ & $S$ & $A$ & $\mathrm{~L}$ \\
\hline $\begin{array}{l}\text { Dental } \\
\text { chaetae }\end{array}$ & $\begin{array}{l}5 \text { (some } \\
\text { spinose) }\end{array}$ & 6 & 5 & 6 & 6 & 6 & 6 & 0 & 6 (3 spines) \\
\hline Plurichaetose & $?$ & $\mathrm{P}$ & $A$ & $A$ & $\mathrm{P}$ & $A$ & $\mathrm{P}$ & $P$ & $A$ \\
\hline Ant IV/III & $\begin{array}{c}\text { ang IV }< \\
\text { ant III }\end{array}$ & $\begin{array}{c}\text { ant IV< } \\
\text { ant III }\end{array}$ & ant IV>ant III & ant IV>ant III & $\begin{array}{l}\text { ant IV< ant III } \\
\text { IV telescopic }\end{array}$ & ant IV $\geq$ ant III & ant IV>ant III & $\begin{array}{c}\text { ant IV> } \\
\text { ant III }\end{array}$ & ant IV $<$ ant III \\
\hline $\begin{array}{l}\text { S chaetae } \\
\text { Abd I-IV }\end{array}$ & $?$ & $?$ & $2,1,1,1$ & $?$ & $2,2,2,1$ & $2,1,1,1$ & $2,2,1,1$ & $?$ & $?$ \\
\hline $\begin{array}{l}\text { Size sensorial } \\
\text { rasp }\end{array}$ & $\mathrm{P}$ & $\mathrm{La}$ & A & $\mathrm{P}$ & $\mathrm{Sm}$ & $?$ & $\mathrm{La}$ & $?$ & $\mathrm{La}$ \\
\hline $\begin{array}{l}\text { Clavate tenent } \\
\text { hairs (no) }\end{array}$ & $A$ & A & $P(1)$ & $P(1)$ & $P(3)$ & A & $P(2)$ & $\mathrm{P}(3)$ & $A$ \\
\hline Size (mm) & $?$ & 2 & 1 & $0.5-1.0$ & $1-1.4$ & 0.85 & 2.15 & 1 & 1 \\
\hline Maxillary teeth & $?$ & 11 & 7 & 1 & 6 & 5 & 11 & $?$ & 1 \\
\hline $\begin{array}{l}\text { Ocelli (each } \\
\text { side) }\end{array}$ & 0 & 8 & 8 & 8 & 8 & 8 & 8 & 8 & 8 \\
\hline $\begin{array}{l}\text { S chaetae } \\
\text { Ant IV }\end{array}$ & $?$ & $?$ & 5 & $?$ & 5 & $?$ & 6 (S7 La) & $?$ & 9 \\
\hline Cuticle & $?$ & fine & fine & $?$ & coarse & fine & coarse & $?$ & $?$ \\
\hline B on labium & $?$ & $?$ & $\mathrm{P}$ & $?$ & $?$ & $?$ & $?$ & $?$ & $P$ \\
\hline $\begin{array}{l}\text { Chaetae on } \\
\text { Th I }\end{array}$ & $?$ & $?$ & $3+3$ & $?$ & $4+4$ & $3+3$ & $10+10$ & $?$ & $?$ \\
\hline $\begin{array}{l}\text { Chaetae } \\
\text { between S } \\
\text { chaetae on } \\
\text { Th II }\end{array}$ & $?$ & $?$ & $\begin{array}{l}1+1 a \\
2+2 p\end{array}$ & $?$ & $\begin{array}{c}2+2 m \\
2+2 p\end{array}$ & $\begin{array}{l}1+1 a \\
2+2 p\end{array}$ & 13 & $?$ & $?$ \\
\hline Ant III organ & $\begin{array}{l}2 \text { francisque } \\
\text { shaped in } \\
\text { fold }\end{array}$ & $\begin{array}{l}2 \text { francisque } \\
\text { shaped in } \\
\text { fold }\end{array}$ & $\begin{array}{l}2 \text { globular } \\
\text { sensilla }\end{array}$ & $\begin{array}{c}2 \text { curved sensilla } \\
\text { in a cuticle pocket } \\
\text { with } 1+1 \mathrm{~S} \\
\text { chaetae laterally }\end{array}$ & $\begin{array}{l}2 \text { sensilla } \\
\text { straight in } \\
\text { granulated pit }\end{array}$ & $\begin{array}{l}2 \text { globular } \\
\text { sensilla }\end{array}$ & $\begin{array}{l}\text { pointed, } \\
\text { straight, in } \\
\text { deep fold }\end{array}$ & $?$ & $\begin{array}{l}2 \text { francisque } \\
\text { shaped in fold }\end{array}$ \\
\hline Supra linguae & $?$ & $5+5$ teeth & $?$ & $?$ & $?$ & $?$ & normal & $?$ & smooth \\
\hline $\begin{array}{l}\text { Labial } \\
\text { chaetae E, F }\end{array}$ & $?$ & $?$ & $E=F$ & $E \geq F$ & $?$ & $?$ & L absent & $?$ & $?$ \\
\hline $\begin{array}{l}\text { Head } \\
\text { chaetotaxy }\end{array}$ & $?$ & $?$ & c1 absent & $?$ & $\begin{array}{c}\mathrm{c} 1, \mathrm{c} 2, \\
\mathrm{p} 1, \mathrm{p} 2, \mathrm{p} 3 \\
\text { present, } 15+ \\
15 \text { between } \\
\text { and anterior } \\
\text { to ocelli }\end{array}$ & $\begin{array}{l}\text { c1, c2 absent } \\
\text { p1, p2, p3 } \\
\text { present }\end{array}$ & $\begin{array}{c}\text { Plurichaetose } \\
\text { Vi, V2 } \\
\text { present, c1, } \\
\text { c2 present, } \\
70 \text { chaetae } \\
\text { between }\end{array}$ & $?$ & $?$ \\
\hline
\end{tabular}


Abbreviations. abd - abdomen, ant - antenna, s - S-chaetae (former "sensilla"), th - thorax, PAO - postantennal organ, TT tibiotarsal hairs, SAMA - South Australian Museum.

The characters used in the descriptions are those in common use for Brachystomellidae as described in Massoud (1967), Naj et al. (2005) and Fjellberg (1998) but with an emphasis on the arrangement of S-chaetae on the abdomen.

\section{RESULTS}

\section{Family Brachystomellidae Stach, 1949 Key to Australian genera}

1 Furca completely absent, body slightly dorso-ventrally flattened, pink or dark red ..............................Setanodosa (4 spp.)

- Furca present, even if as a remnant with microchaetae, body cylindrical, colour variable .................................................... 2

2 Apex of maxilla elongated................................................... 3

- Apex of maxilla, broad, square or rectilinear ......................... 5

3 PAO absent, ant III and IV fused dorsally, sensorial rasp on ant IV large, well developed, with 80 specialised S-chaetae, distal sensory S-chaeta S7 on ant IV enlarged, in a pit............ .. Salvarella $(1 \mathrm{sp}$.

- PAO present, ant III and IV fused dorsally or not, sensorial rasp on ant IV small, consisting of up to 10 specialised Schaetae, no single distal S-chaetae enlarged on ant IV, or in a

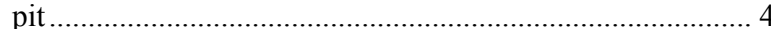

4 Maxilla with two distinct lamellae with total of eight medium sized teeth; antennal segments IV telescoped into III, ant IV < ant III, slightly plurichaetose, ordinary chaetae long ....

Cassagnella $(1 \mathrm{sp}$.

- Maxilla with narrow lamellae, up to seven teeth, antennal segments IV not telescoped into III, ant IV $<>$ ant III, body not plurichaetose, ordinary chaetae short, reduced in number Rapoportella (1 sp.)

5 PAO present ... 6

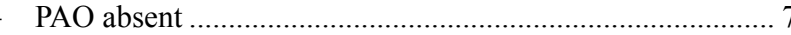

6 Mucro with straight lamellae.......... Brachystomella (10 spp.)

- Mucro with pocket shaped lamellae .........Massoudella (1 sp.)

7 Mucro with straight lamellae.........................Bonetella (1 sp.)

- Mucro with pocket shaped lamellae.. Subclavontella (2 spp.)

\section{Summary of Australian genera and species}

Species are all listed with their distributions in the online catalogue by Greenslade (2017).

\section{Bonetella Stach, 1949}

Only one species described from several specimens found on a fungal fruiting body from Western Australia. It is only known from the type locality (Middle Swan).

\section{Brachystomella Ågren, 1903}

This genus includes eight endemic species and two exotic species one of which is found abundantly in arable and pasture soils of farming land. The abundance and distribution of one exotic species, Brachystomella platensis Najt \& Massoud, 1974 can indicate land condition, in particular the ecological effects of conservation farming. Although most species favour moist habitats, one endemic species, Brachystomella dianae Greenslade \& Najt, 1987b occurs in the arid/semi arid zones and survives dry periods by losing water and entering anydrobiosis. Another, Brachystomella solidaria Greenslade \& Najt, 1987b, is only found in montane grassland and heathland and is at risk from climate change.

\section{Massoudella Ellis \& Bellinger, 1973}

Ellis and Bellinger erected the genus as a replacement name for Australella Arlé, 1959 which was preoccupied. Only one species has been described, which is only found on fungal fruiting bodies.

\section{Cassagnella Najt \& Massoud, 1974}

Only one species has been described from Australia but undescribed species are known from Tasmania and other localities in Victoria.

\section{Rapoportella Ellis \& Bellinger, 1973}

Only one species is known from eucalypt woodland on Kangaroo Island but a new species is described here.

\section{Salvarella Greenslade \& Najt, 1987a}

A single species has been described from a single specimen living in a small, isolated remnant of native vegetation in the wheat growing area of south western Western Australia (Greenslade \& Najt, 1987a).

\section{Setanodosa Salmon, 1942}

The four species known are tolerant of dry conditions and can adopt an anhydrobiotic state in adverse conditions. One species is frequent in arid and semi-arid zones occurring in leaf litter under chenopodiaceous shrubs and open woodland. Another species is frequent under loose bark of eucalypt trees in sub-humid woodland. Generally species are only found in the southern half of Australia.

\section{Subclavontella Stach, 1949}

The two species in this endemic genus are almost exclusively found on fungal fruiting bodies in south eastern Australia.

\section{Genus Cassagnella Najt \& Massoud, 1974}

Type species. Cassagnella alba Najt \& Massoud, 1974.

The type species C. alba was described from Argentina. The authors of the genus illustrated the morphology of the type species in ten figures and included the dorsal chaetotaxy. They noted that the chaetotaxy of the head is unique, probably meaning it was plurichaetose, and that the elongated form of the maxilla, was similar to that of Rapoportella Ellis \& Bellinger, 1973. It is also similar in elongation to that of Salvarella Greenslade \& Najt, 1987a. Najt \& Weiner (2001) provided an additional diagnosis for Cassagnella noting that species in the genus are plurichaetose. These authors did not differentiate the genus clearly from Rapoportella.

Greenslade (1974) transferred the Australian Brachystomella anomala Womersley, 1933 to Cassagnella but without morphological justification. Najt \& Weiner (2001) also listed this species in Cassagnella and provided a key to then three species in the genus. They distinguished $C$. anomala from the other two species by the presence of pigment, the absence of teeth on the claw, the post anten- 

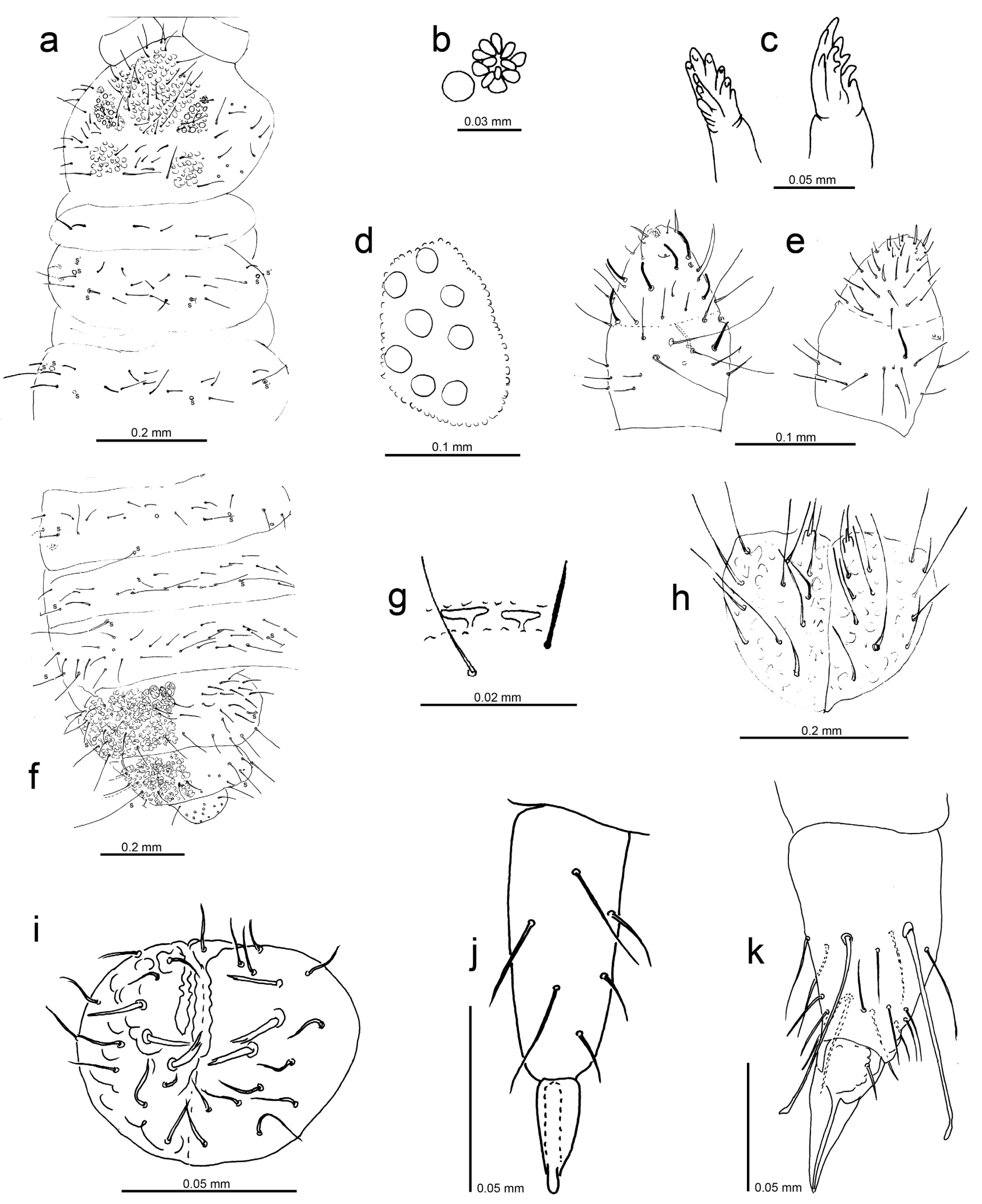

Fig. 1. Cassagnella anomala (Womersley, 1933). a - dorsal head and thoracic chaetotaxy; b - right anterior ocellus and postantennal organ; c - left maxilla lateral and ventral views; $d$ - left ocelli patch; e - segments III and IV of left antenna, dorsal view (left) and ventral view (right) showing enlarged chaetae of sensorial rasp; $\mathrm{f}$ - abdominal chaetotaxy; $\mathrm{g}$ - antennal III organ; $\mathrm{h}$ - labium; $\mathrm{i}$ - male genital plate; $\mathrm{j}$ - dens and mucro; $\mathrm{k}$ - tibiotarsus III internal view.

nal organ with 12 rather than 8 tubercles and structure of antennal III organ. They noted that some paratype material came from the State of South Australia (Najt \& Weiner, 2001) but the species is only known from Victoria. There are currently three species in the genus (Najt \& Weiner, 2001), one from Australia and two from South America.

Generic diagnosis (modified from Najt \& Massoud, 1974; Najt \& Weiner, 2001). Largish animals for family; 

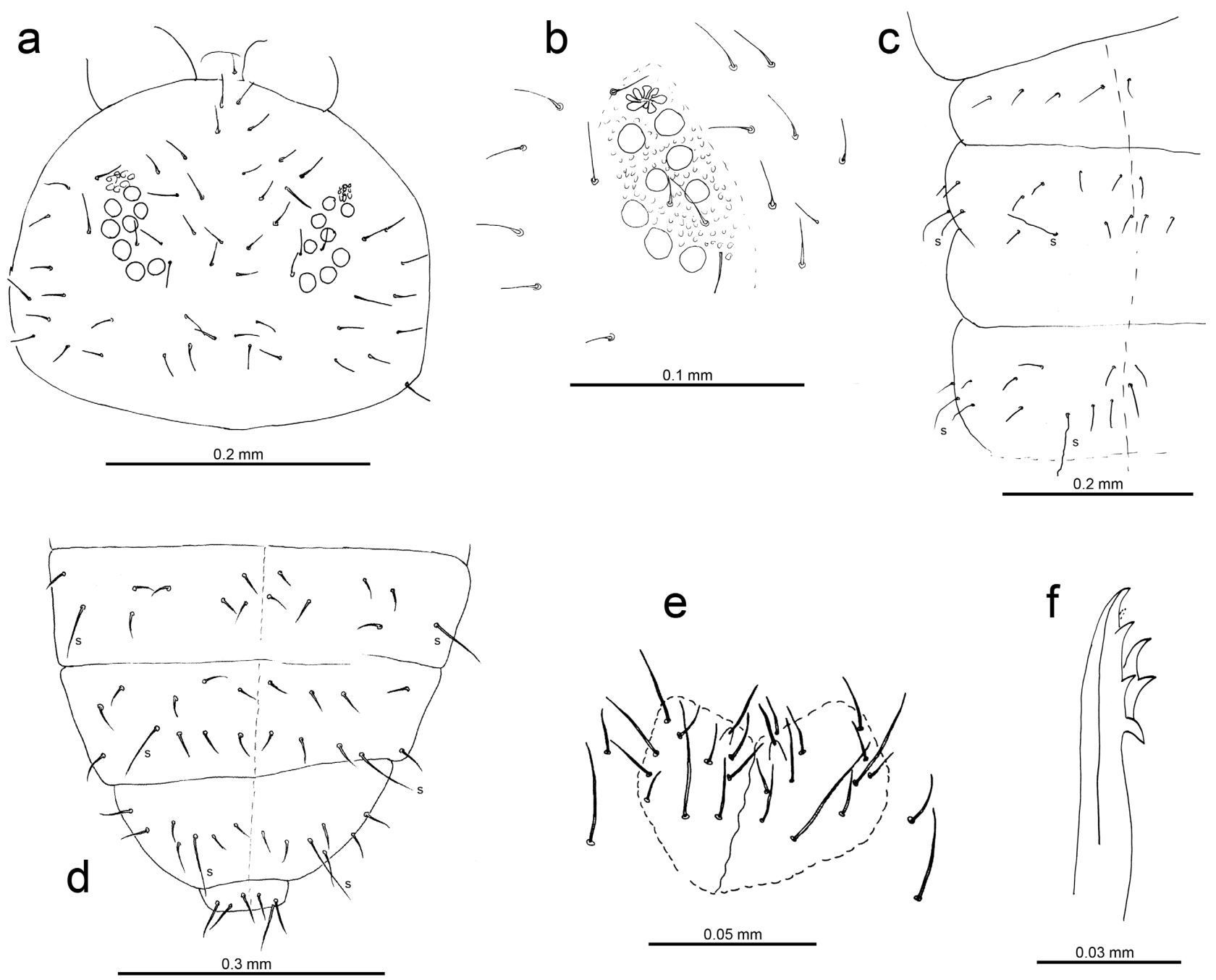

Fig. 2. Rapoportella edwardi sp. n. a - dorsal head chaetotaxy; b - left ocelli and postantennal organ; c - thoracic chaetotaxy, left side only; $\mathrm{d}$ - abdomen III to VI dorsal chaetotaxy; e - labium; $\mathrm{f}$ - left maxilla, dorsal view.

usually coloured dark blue with reddish tinge, eye patch pigmented or not. Antennae shorter than head diagonal; antennal IV globular, shorter than antennal segment III, slightly retracted into III and with small, ventral, sensorial rasp. Head chaetotaxy with dx usually present. Ocelli $8+$ 8; postantennal organ with eight or more tubercles, starshaped; maxilla with elongated head, longer than broad, and with two toothed lamellae. Two S-chaetae on abdominal segments II and III (apparently) as well as on abdominal segment I. Legs with two adjacent long internal chaetae and one external, clavate or not; furca short; dens with five chaetae; mucro present, mucronal lamellae only slightly broadened, separate from dens.

Individuals of a few other Australian undescribed species as with $C$. anomala, all possess plaques of cuticle formed by coarse secondary granules on some tergites, particularly on head and abdominal segments IV and V.

Description of genus. Cassagnella has an additional Schaeta not only on abd I, which is a distinct character for the family Brachystomellidae, but also on abd II and III. Although this character is not noted in the type species, $C$. $a l b a$, they are shown in Fig. 2A (Najt \& Massoud, 1974) for abdominal segments I, II and III. In the description of
C. sergoi Najt \& Weiner, the extra S-chaetae are not only figured (Fig. 1 in Najt \& Weiner, 2001) but also included in the description (s per half tergum as $0,2,2 / 2,2,2,1,1)$ but without commenting as to whether this pattern is a generic character or not. This character is included as present in the species examined in genera Cassagnella and Brachystomellides in Najt et al. (2005). The same formula is also present in the holotype of Brachystomella fungicola Womersley (P. Greenslade \& J. Najt, unpubl. results), which has been variously placed in the genera Australella and then Brachystomellides by Massoud (1967) and Najt \& Weiner (1996). It is possible that the $\mathrm{S}$ formula is a diagnostic character for certain southern genera of Brachystomellidae.

Several other species of Cassagnella from Australia are in collections and await description. They have been collected from south-eastern parts of South Australia, Tasmania and other sites in Victoria. Characters distinguishing species include distribution and number of cuticular plaques dorsally on body, tenent hairs clavate or not, teeth or not on claw, form of male sexual characters and of sensorial rasp on antenna IV. The genus seems restricted in Australia to south-eastern cool moist forests. The redescription below of $C$. anomala was largely the work of J. Najt. 

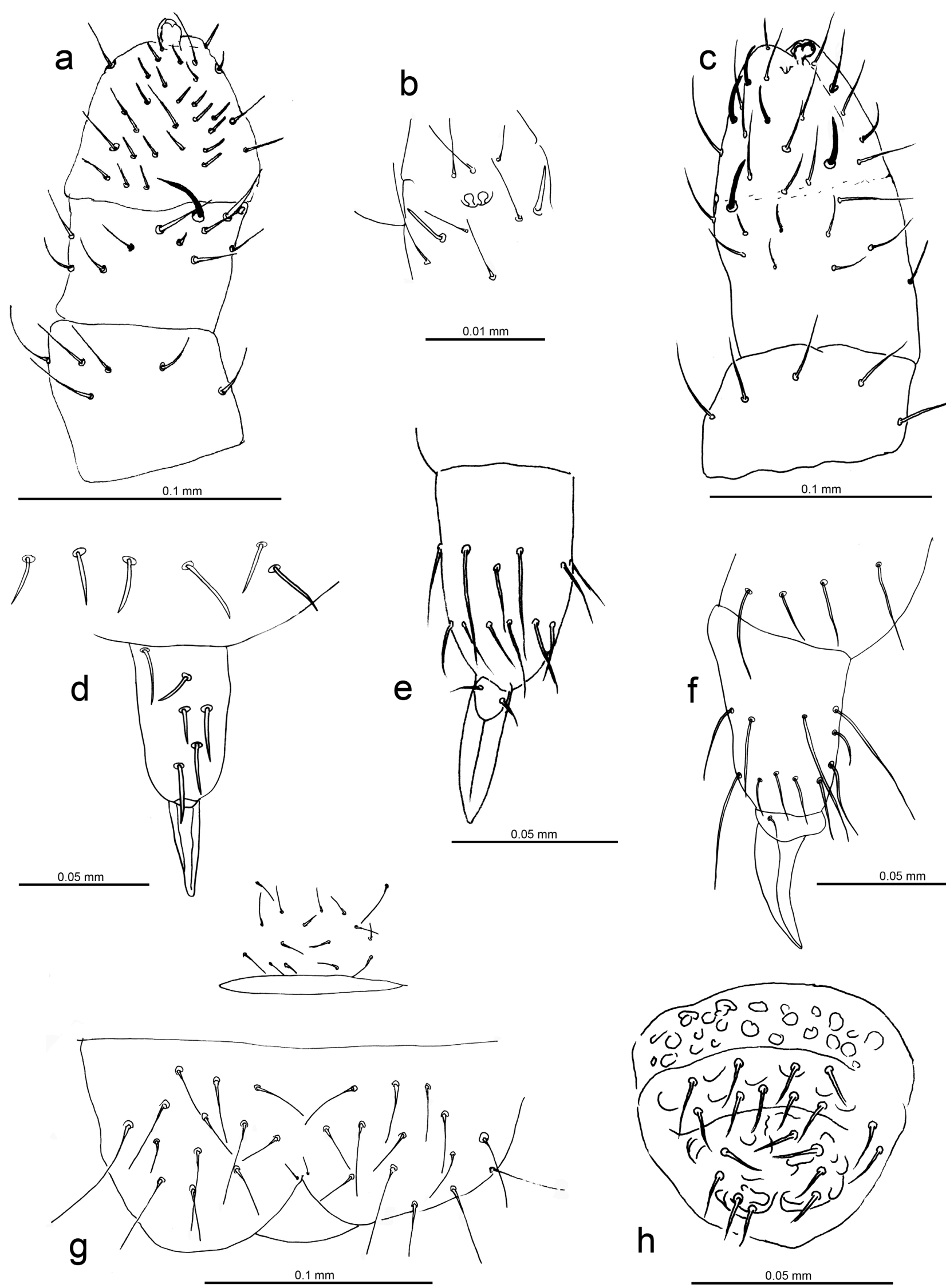

Fig. 3. Rapoportella edwardi sp. $\mathrm{n}$. a - left ant II to IV ventral view; b - ant III organ; c - left ant II to IV dorsal view; d - distal manubrial chaetae, dens and mucro; e - tibiotarsus III internal view; $\mathrm{f}$ - tibiotarsus II lateral view; $\mathrm{g}$ - female genital plate and anal lobes; $\mathrm{h}$ - male genital plate. 


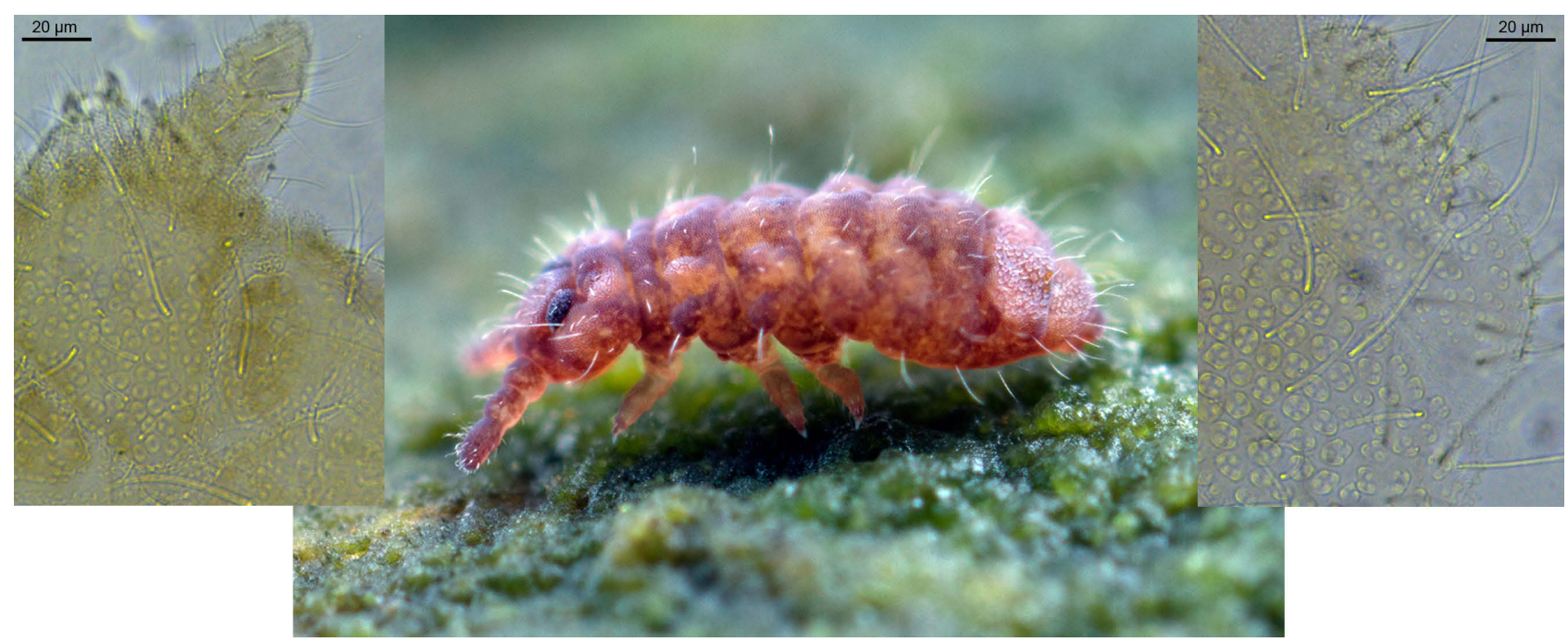

Fig. 4. Colour photograph of live Cassagnella anomala Womersley from Kallista, Dandenong Ranges (@ N. Porch). Insertions depict coarse areas of cuticle on head and abdominal segments IV + V.

\section{Cassagnella anomala (Womersley, 1933)}

(Fig. 1, Table 1)

Brachystomella anomala Womersley, 1933: 60.

Type material examined. Lectotype male, SAMA I22407, VICTORIA, Dandenong Ranges, Sassafrass, xii.1931, leg. H.G. Andrewartha, det. H. Womersley as Brachystomella anomala sp. n. and labelled Cotype (SAMA I 22407). Lectotype designation by Greenslade (1994). Paralectotypes: 2 juveniles, SAMAI22408, SAMAI22409. VICTORIA, Dandenong Ranges, Sassafras, xii.1931. H.G. Andrewartha, det. H. Womersley as Brachystomella anomala sp. n., both labelled Cotype.

Other material. 43 specimens in alcohol (SAMA). Australia, Victoria, Dandenong Ranges National Park, approximately 0.15 to $0.4 \mathrm{~km} \mathrm{WNW}$ of Kallista roundabout, $405 \mathrm{~m}, 37^{\circ} 53^{\prime} \mathrm{S}$, $145^{\circ} 22^{\prime} \mathrm{E}$, pitfalls, 22.ii.-14.iii.2014, N. Porch and A. Lodewyke.

\section{Redescription}

Colour. Blue-maroon, very dark, slightly paler mottles dorsally, paler ventrally.

Size. Male adult from $1.6 \mathrm{~mm}$ up to $2.17 \mathrm{~mm}$, female adult $1.65 \mathrm{~mm}$; pre-adults between 1.55 and $1.64 \mathrm{~mm}$.

Habitus. Slightly dorso-ventrally flattened body, bulbous, paratergites slightly enlarged; abd V longer than IV and plate shaped; abd VI very short, hardly visible dorsally.

Cuticle. Body with coarse cuticular granules, dorsal parts of head and body possessing secondary granules clustered together in form of tertiary rosettes comprising 4 to 12 secondary granules arranged as follows: head central field anterior to vertex, ocular field, occipital field; abdomen IV - all tergite surface; abdomen V - all tergite surface; abdomen VI - few granules; dorso-lateral lobe on segments th II projecting slightly with discrete area of enlarged cuticle granules and 2 long chaetae.

Dorsal chaetotaxy. Clothing abundant with very long chaetae especially laterally, longer or equal to dorsal length of segment. Two types of chaetae present on body: ordinary pointed tapering chaetae of differing lengths and longer fine S-chaeta; head and body mildly plurichaetose consequently asymmetries and displacements present.
Ratios. Abd III lat chaetae : segment length $=15: 13$; abd IV $=25: 25$; abd V of $\mathrm{p} 1: \mathrm{p} 2: \mathrm{p} 3 \mathrm{~S}:$ segment length $=$ $1: 1: 3: 2$.

Head and antennae. Antenna shorter than the head diagonal. Antennal segment I with 7 chaetae, antennal II with 13 chaetae, sensory organ of Antennal III formed by two elongate t-shaped clubs bent in the same direction, 2 long, fine, sub cylindrical guard S-chaetae, and one small, exposed, latero-ventral S-chaeta. Antennal segment IV slightly shorter than III, with slightly trilobed apical vesicle, six indistinct long, sub-cylindrical S-chaeta. The ventral surface of ant IV with 8 short, thick chaetae with obliquely blunt tips in a irregular sensorial rasp. Eight ocelli on each side of the head set in pigmented overall area; 2 preclypeal chaetae. Post antennal organ with 9 to 12 tubercles. Buccal cone truncate, labium as in figure with chaeta E much longer than F. Maxilla characteristic of the genus, with eight teeth on two distinct lamellae; the longest with six teeth, the second short with two pointed teeth.

Thorax. Leg III with 2 long chaetae on coxa; tibiotarsus I, II, III with 19, 19, 18 chaetae of which 2 internal and ventral long clavate tenent hairs with crossed tips. Claw with pair of small lateral teeth. Leg III precoxa 2 with five, precoxa 1 with three, coxa with five or six chaetae; trochanter with six chaetae; femur with 11 chaetae (Table 2).

Abdomen. Ventral tube with $2+2$ distal, $1+1$ basal chaetae. Retinacle with $3+3$ teeth, without chaeta on the body. Ratio mucro: dens $=1.2 .5$. Genital plaque of male with 4 to 6 circum-anal chaetae internally, thick and strong. Comments

In the description of $B$. anomala, Womersley records that the ocelli were not on a pigmented eye spot, which

Table 2. Chaetotaxy of legs of Cassagnella anomala.

\begin{tabular}{lcccccc}
\hline & $\begin{array}{c}\text { Precoxa Precoxa } \\
\text { I }\end{array}$ & II & Coxa & Trochanter & Femur & $\begin{array}{c}\text { Tibiotarsus } \\
\text { B+distal whorl }\end{array}$ \\
\hline Leg I & 0 & 0 & 3 & 6 & 13 & $8 / 11$ \\
Leg II & 2 & 2 & 6 & 6 & 13 & $8 / 11$ \\
Leg III & 2 & 2 & 6 & 6 & 13 & $7 / 11$ \\
\hline
\end{tabular}


is unusual for a hemiedaphic species, but his figure shows some pigmentation around each lens. Newly collected species show ocelli patch completely pigmented. He notes that "this species was placed in the genus [Brachystomella] with a considerable amount of doubt, for the structure of the head of the maxilla, the form of the postantennal organ and the strongly granulate cuticle....". Massoud (1967) omitted from his key several species of Brachystomella, including Womersley's Australian anomala, because "the maxilla is totally different to that of Brachystomella species".

There are three type slides listed in Womersley's (1933) original description, all are labelled cotypes. The medium on each is now dark and the slide with lectotype has dried out with the medium cracked. The lectotype has also disintegrated and two paralectotypes are cleared excessively so few details can be recognised. Information from a contemporary of Herbert Womersley at the South Australian Museum said that he used to leave his slides on a window ledge after working on them. The slides were in better condition in 1983 when the description and figures were made. Improvements have been made to the original figures using recently collected topotypes.

It is likely that this species is particularly sensitive to humidity and inhabits sites subject to flooding based on the morphology of the cuticle, i.e., plaques of coarse enlarged granules which could act as a plastron. Several other species of Australian Collembola from excessively humid habitats have similar plaques (Friesea florifera Greenslade \& Deharveng, 1997, Brachystomella solidaria Greenslade \& Najt, 1987, Odontella sp. undescribed). With a gradually drying climate since 1931 when the type specimens were collected it is likely that populations have retreated to humid refugia where they were found in 2013 by Deakin University staff and students. Other humid loving species of Collembola such as genera of Paronellidae and Dicyrtomidae were found abundantly in pitfall traps at Kallista in the Dandenong Ranges that could be threatened with $C$. anomala by a drying climate and by the invasion of an exotic grass into ground layer of the forest.

\section{Genus Rapoportella Ellis \& Bellinger, 1973}

Type species. Probrachystomella rhodosoma Rapoport, 1962.

There are currently 11 described species of Rapoportella. The type species for the genus was established as $P$. rhodosoma by Ellis \& Bellinger (1973) when they erected the genus. Although P. bonariensis (p. 21) and P. rhodosoma (p. 9) were erected and described in the same paper (Rapoport, 1962) and P. rhodosoma was based on an adult male (see Rapoport, 1962 Fig. 59) and published earlier in the paper than P. bonariensis (based on male and female, see Rapoport's Figs 134 and 135), Najt \& Palacios Vargas (1986) synonymised rhodosoma with bonariensis (under the latter name) and incorrectly gave bonariensis as type species for the genus Rapoportella. These two authors gave no reason for the synonymy in spite of Rapoport (1962) providing several characters to separate the two species and they only had an immature specimen of $R$. bonariensis to examine. Rapoport (1962) noted that bonariensis was larger, it had 6 not 5 setae on the dens, the claw had a ventral tooth and the S-chaetae on the antennae were proportionally much shorter. It is not possible to tell from the figures whether these characters are sufficiently insignificant for synonymy. Therefore the validity of the synonymy cannot be resolved without examining type species (which is out of the scope of the current paper) and the synonymy is not accepted here on the basis of lack of evidence. It also seems probable that Najt and Palacios Vargas made a mistake in quoting bonariensis as type of the genus (J. Palacios Vargas in litt.) and rhodosoma remains the type species (by original designation) of Rapoportella.

Generic diagnosis. Small size, adults less than $1 \mathrm{~mm}$ in length; maxilla narrowly elongate with two thin lamellae, both toothed; a reduced number of chaetae especially on head and dens; short ordinary chaetae relative to size of body and so relatively longer S-chaetae, formula $0,2,2 / 2,2,2,1,1$. [Rapoport (1962) quotes the type species, $R$. rhodosoma, as having a formula of $1,2,2 / 2,1-2,1-2,3,2$ (which cannot be correct)]; a small PAO with fewer than 10 tubercles; cuticle not coarsely granulate and without secondary rosette-shaped granules; absence of clavate tenent hairs.

\section{Rapoportella edwardi sp. n.}

(Figs 2, 3)

ZooBank taxon LSID:

268BB7AC-58A4-4E6D-8B18-75CDE3C08971

Type material. Holotype female, Australia, "VICTORIA, Garibaldi, $37^{\circ} 5.131^{\prime} \mathrm{S}, 143^{\circ} 55.3^{\prime} \mathrm{E}, 214 \mathrm{~m}$ a.s.l., forest remnant, 24.iii.2010, leg. L. Bell, P. Greenslade”. Paratype male, same locality and date as holotype. Both in SAMA.

\section{Description}

Colour. Pale grey.

Size. Small species; length $0.9 \mathrm{~mm}$ for both female and male.

Habitus. As for Brachystomellides but slightly dorsoventrally flattened.

Cuticle. Cuticular granules fairly well developed, with round secondary granules, even in size over all dorsal parts of tergites, absent ventrally and from antennae; no rosette amalgamation of secondary granules seen on the body (unlike C. anomala); six granules between a1 chaetae on abd III; four granules between al chaetae of abd V.

Dorsal chaetotaxy. Not plurichaetose; meso-chaetae on tergites all short, fine; no distinct macrochaetae; S-chaetae long, fine, pointed, becoming longer posteriorly; on abd V length of S-chaeta 3.5 times length of ordinary, adjacent p3 meso-chaetae; head with reduced and shorter chaetotaxy with 20 median chaetae (compared to 30 in C. alba). Additional S-chaeta laterally on abdominal segments I, Schaetal formula as 2,2/2,1,1,1,1 from abd III to V p5, p3, $\mathrm{p} 4, \mathrm{p} 3$. No $\mathrm{m}$ chaetae present dorsally on any segment. 3 +3 chaetae between S-chaetae on abd II, $3+4$ chaetae on abd III. Chaetae present on segments as follows: thorax I, 4; thorax II and III, a1, 3, 4, 5, p 1, 2, 4s, 5; abd I, II as 
Table 3. Characters separating type species of their genera, Cassagnella alba Najt \& Massoud, 1974 and Rapoportella rhodosoma (Rapoport, 1962) and non-type R. edwardi sp. n. taken from Najt et al. (2005) and original descriptions. Coding by Najt et al. (2005). Distinguishing characters signified in bold.

\begin{tabular}{|c|c|c|c|c|}
\hline Characters & Cassagnella alba & Rapoportella rhodosoma & Rapoportella edwardi & Notes \\
\hline Sensorial rasp & 27 chaetae & unknown & 10 chaetae & \\
\hline Maxillary lamellae & 2 lamellae & 2 lamellae & 2 lamellae & R. rhodosoma wrongly coded \\
\hline Chaeta d on head & $8+8$ & $6+6$ & $6+6$ & \\
\hline Chaetae c on head & $6+6$ & $4+4$ & $5+5$ & Variable \\
\hline Chaetae $p$ on head & $3+3$ & $2+2$ & $4+4$ & Variable \\
\hline S-chaeta a4 on Th II & present & absent & present & \\
\hline S-Chaeta a4 on Th III & present & absent & present & \\
\hline Chaeta a5 th II & single & single & single & R. rhodosoma wrongly coded \\
\hline Chaetae in $\mathrm{m}$ row on Th II & $5+5$ & absent & absent & \\
\hline Coxa II chaetae & 7 & 6 & 6 & \\
\hline Trochanter I, II chaetae & 6 & 5 & 6 & \\
\hline Trochanter III chaetae & 6 & 4 & 6 & \\
\hline Chaetae on femur & 11 & 10 & 11 & \\
\hline TT A1 length versus internal claw & longer than claw & equal & longer than claw & \\
\hline TT B4, 5 & longer than claw & short & longer than claw & \\
\hline TT M & present & absent & absent & \\
\hline Dorsal S-chaetae on Abd II & $2+2$ & $1+1$ & $1+1$ & \\
\hline Dorsal S-chaetae on Abd III & $2+2$ & $1+1$ & $1+1$ & \\
\hline Dorsal S-chaeta Abd V & p5 & p2 & p5 & \\
\hline Abd III sternite chaetae & $3-15$ & $2+2$ & $3+4$ & Variable \\
\hline $\begin{array}{l}\text { VT chaetae } \\
\text { Length of S chaeta compared to Abd V }\end{array}$ & $\begin{array}{c}4+4 \\
\text { longer }\end{array}$ & $\begin{array}{l}3+3 \\
\text { shorter }\end{array}$ & $\begin{array}{c}2+2 \\
\text { shorter }\end{array}$ & Variable \\
\hline
\end{tabular}

figure; abd III a1, 3, 4 and p 1, 2, 4, 5; abd IV a1, a2, a5 and p1, p2, p3 and p4S, p5; abd V with a 4, 5 chaetae; abd VI with a1 and p 2, 3 dorsally.

Ratios. Head diameter : antennal length $=2: 1$ in both sexes. Abd $\mathrm{V} \mathrm{p} 1: \mathrm{p} 2: \mathrm{p} 3 \mathrm{~S}:$ length of segment $=$ $1.5: 1: 3.5: 3.8$.

Head and antennae. Antenna shorter than the head diagonal. Antennal segment I with 7 chaetae; antennal II with 13 chaetae of which one ventral chaeta is short and curved; antennal segment III with 19 chaetae. Antennal segment IV slightly shorter than II, fused dorsally with ant III, apical vesicle tendency to divide at tip; six more or less distinct S-chaetae; ventral surface of ant IV with 10 short thickish chaetae with obliquely blunt tips in a sensorial rasp, organite present but ms replaced by fine thin short chaeta. Sensory organ of Antennal III formed by two round slightly club-shaped bulbs behind low cuticular fold, 2 long, thick, curved guard S-chaetae, one dorsal and one ventral. Eight ocelli on each side of the head. Post antennal organ with nine ( 8 to 10 ) tubercles, about equal in size to anterior ocellus, three ocular chaetae; v1, v2 absent. Medial dorsal chaetotaxy of head reduced; ao short, fine; do (dx) chaeta present but sd and d-chaetae reduced to total of 20; with sd1, 3, 4, 5 chaetae only i.e. 4 in total; d1, d2 axial, d3, d4, and d5 i.e. 5 in total. Buccal cone truncate, labium with $\mathrm{L}$ in tubular insertion and 10 other chaetae, E much longer than F; labrum with 2, 3, 3, 4 chaetae. Maxilla characteristic of the genus, with 2 narrow lamellae carrying $4+$ 3 teeth; cardo elongated as for genus, posterior part of head broad. Ventral head with $2+2(1)$ chaetae along midline.

Thorax. Tibiotarsus I, II III with 19, 19, 18 chaetae of which ventral 2 (B5, B6) are long tenent hairs, dorsal A1 also long but fine. Claw without external or internal teeth. No clavate tenent hairs. No ventral chaetae on thoracic sternites. Ratio internal long internal $B$ chaetae : adjacent ordinary chaetae : internal claw length $=3: 1: 1.75$.
Abdomen. Ventral tube with $3+3$ chaetae. Retinacle with $3+3$ teeth, without chaetae on the body. Manubrium with 4 distal chaetae. Dens with 5 (4) chaetae; mucro straight with broad lamella; furcal subcoxa with $2 / 3$ chaetae. Ventral anal lobes with 14 chaetae plus $1+1$ internal microchaetae. Ratio mucro: dens $=1: 2.5$. Genital plaque of male with $4+4$ internal small spine-like chaetae and 9 + 9 circum-aperture chaetae more externally, surrounding plaque with conspicuous coarse secondary tubercles. Female with 16 chaetae, all anterior to aperture.

Etymology. Named for my grandson Eddie G.

Ecology. Rapoportella edwardi was found in soil from a rare small remnant eucalypt open forest with a heathy understorey in a part of south-eastern Victoria where nearly all native vegetation was cleared for agriculture and mining over 100 years ago.

\section{Comments}

The new species differs from $R$. karta Greenslade \& Najt, 1987b, the only other Australian species in the genus, in that it has more tubercles to the post antennal organ, the tibiotarsal hairs are longer, the sensorial rasp consists of more chaetae and the claw has no tooth. The S-chaetal formula was given for R. karta as $0,2,2 / 1,1,1,1,1$.

Greenslade \& Najt (1987b) provided a table of species and significant characters for the genus but did not include the arrangement of S-chaetae as a character which are figured or described for nearly all other Rapoportella species in the literature as 2,2/2,1,1,1,1 but with some variations.

Because the genera Cassagnella and Rapoportella were not precisely distinguished when erected, $R$. edwardi $\mathrm{sp}$. n. was originally placed with Rapoportella with some doubts. It differs from species of Cassagnella in being smaller, in the absence of plurichaetotaxy, in having much shorter and fewer ordinary chaetae and no areas of coarse secondary granules on the abdomen. Moreover the structure of 
the maxilla differs in being narrower but the postantennal organ being stellate in shape is similar to Cassagnella.

\section{DISCUSSION}

I provide here, for the first time since Womersley (1939), a dichotomous key to Australian genera in the family Brachystomellidae and some ecological notes on the distributions and species richness of two native genera, both of which are only found in native vegetation. The descriptions confirm that, despite some similarities in the characters of the two genera, they are distinct morphologically. Both species are at risk because both are dependent on intact native vegetation.

A phylogenetic tree for 16 genera of Brachystomellidae based on morphology was constructed by Najt et al. (2005) who relied on 54 characters for 26 species of Brachystomellidae including the type species of the two genera rediagnosed here, Cassagnella alba and Rapoportella rhodosoma. The tree produced indicated monophyly of both genera but was not so clear for several non-Australian genera except Brachystomella. The characters that separated Cassagnella and Rapoportella (Najt et al., 2005) were mainly chaetotaxic with $R$. rhodosoma possessing fewer and shorter chaetae than $C$. alba. Twenty one characters differed in these two genera and are listed in Table 3. Two may have been incorrectly coded but there is some variability within the genus in tibiotarsal chaetotaxy in particular. At least half the characters are generically diagnostic and $R$. edwardi sp. n. complies with generic characters for $R$. rhodosoma. The characters in bold in Table 3 (all are chaetotaxic) are sufficient to show the genera are distinct and to characterise them.

ACKNOWLEDGEMENTS. Thanks are due to Victorian National Parks for permission to collect in the Dandenong Ranges. Much gratitude is owed by the author to J. Najt for her knowledge of the family Brachystomellidae and her guidance to the author in gaining an understanding of the taxonomy of the family. I am grateful to the anonymous referees who greatly improved the manuscript. It should be noted that the authorship of this paper was, in the first version, shared with J. Najt, but her name was removed at the request of the editor.

\section{REFERENCES}

Ågren H. 1903: Diagnosen einiger neuen Achorutiden aus Schweden. - Entomol. Tidskr. 24: 126-128.

ArLÉ R. 1959: Collembola Arthropleona do Brasil oriental e central. - Arch. Mus. Nac. (Rio de Janeiro) 49: 155-211.

Bellinger P.F., Christiansen K.A. \& Janssens F. 1996-2018: Checklist of the Collembola of the World. URL: http://www. collembola.org (last accessed Feb. 2018).

Ellis W. \& Bellinger P. 1973: An Annotated List of the Generic Names of Collembola (Insecta) and their Type Species. Monografieën van de Nederlandse Entomologische Vereniging No. 7. Nederlandse Entomologische Vereniging, Amsterdam, 74 pp.

FJellberg A. 1998: The Collembola of Fennoscandia and Denmark, Part I: Poduromorpha. Brill, Leiden, 184 pp.
Greenslade P. 1994: Collembola. In Houston W.W.K. (ed.): Zoological Catalogue of Australia. Vol. 22. Protura, Collembola, Diplura. CSIRO, Melbourne, pp. 19-138.

Greenslade P. 2017: Check List for Australian Collembola. Australian Faunal Directory. URL: http://www.environment.gov. au/biodiversity/abrs/online-resources/fauna/afd/COLLEMBOLA/tree.html (last accessed July 2017).

Greenslade P. \& Najt J. 1987a: Collemboles Brachystomellinae de l'Australie. II. Le genre Salvarella n.g. - Rev. Fr. Entomol. 9: $115-119$.

Greenslade P. \& NaJt J. 1987b: Collemboles Brachystomellinae de l'Australie. I. Les genres Brachystomella et Rapoportella. - Ann. Soc. Entomol. Fr. (N.S.) 4: 435-453.

Mari Mutt J.A. \& Bellinger P.F. 1996: Supplement to the Catalog of the Neotropical Collembola - August 1989 to April 1996. — Caribb. J. Sci. 32: 166-175.

Massoud Z. 1967: Monographie des Neanuridae, Collemboles Poduromorphes à pièces buccales modifiées. Doctoral thesis, Université de Paris, 399 pp.

Massoud Z. \& Thibaud J.M. 1980: Les Collemboles des Petites Antiles II - Neanuridae. - Rev. Ecol. Biol. Sol 17: 591-605.

Mendonça M.C. DE \& Fernandes L.H. 1995: Nova espécie de Rapoportella Ellis \& Bellinger, 1973 do Brasil (Collembola: Neanuridae). - Bol. Mus. Nac. (N.S.) (Zool.) 360: 1-6.

NaJt J. \& Massoud Z. 1974: Contribution à l'étude des Brachystomellinae (Insectes, Collemboles) I. Nouvelles espèces rècoltées en Argentine. - Rev. Ecol. Biol. Sol 11: 367-372.

Najt J. \& Palacios Vargas J. 1986: Nuevos Brachystomellinae de Mexico (Collembola, Neanuridae). — Nouv. Rev. Entomol. 3: $457-471$.

NAJT J. \& WeInER W.M. 1996: Geographical distribution of Brachystomellinae (Collembola: Neanuridae). - Pan-Pac. Entomol. 72: 61-69.

NAJt J. \& Weiner W. 2001: The species of Cassagnella Najt \& Massoud, 1974 (Collembola, Brachystomellidae). — Acta Zool. Cracov. 44: 419-422.

Najt J., Weiner W.M. \& Grandcolas P. 2005: Phylogeny of the Brachystomellidae (Collembola) - were the mandibles ancestrally absent and did they reappear in this family. - Zool. Scr. 34: 305-312.

RAPOPORT E.H. 1962: Colembolos de Bahía Blanca (Argentina) III. - Publ. Inst. Edafol. Hidrol. 2: 3-24.

SALMON J.T. 1942: New genera and species of New Zealand Collembola and a discussion on Entombrya atrocincta Schött. Rec. Domin. Mus. 1: 55-60.

STACH J. 1949: The Apterygotan Fauna of Poland in Relation to the World-Fauna of this Group of Insects. Families: Neogastruridae and Brachystomellidae. Acta Monographica Musei Historiae Naturalis. Polska Akademia Umiejętności, Kraków, 341 pp., 34 pls.

Thibaud J.-M. 1993: Les Collemboles des Petites Antilles VI. Interstitiels terrestres et marins. - Rev. Fr. Entomol. 15: 69-80.

Thibaud J.-M. \& Massoud Z. 1983: Les Collemboles des Petites Antilles III. Neanuridae (Pseudachorutinae). - Rev. Ecol. Biol. Sol 20: 111-129.

WomersLey H. 1933: A preliminary account of the CollembolaArthropleona of Australia. I. Poduroidea. - Trans. R. Soc. Sth Aust. 57: 48-71.

Womersley H. 1939: Primitive Insects of South Australia. Government Printer, Adelaide, 322 pp.

Received September 17, 2017; revised and accepted December 13, 2017 Published online March 8, 2018 